8 Whitehead A, Whitehead J. A general parametric approach to the metaanalysis of randomised clinical trials. Stat Med 1991;10:1665-77.

9 Wehr R, Gibson J, Epinette W, Pincus S, Chesnut C, Goffe B, et al. The safety of topically applied calcipotriene ointment $0.005 \%$ (a vitamin $\mathrm{D}_{3}$ analogue) as measured by blood, urine and bone density analysis in psoriatic patients [abstract]. Skin Pharmacol 1992;5:206-7.

10 Griffiths WAD. Comparison of calcipotriol ointment and betamethasone ointment in the treatment of psoriasis vulgaris (parallel group). Presented at Daivonex, calcipotriol. A totally new treatment in psoriasis [abstract] Athens, Greece, 1991

11 RT Plott. A double-blind study comparing the efficacy of diflorasone diacetate ointment $0.05 \%$ vs calcipotriene ointment $0.05 \%$ in the treatment of psoriasis [abstract]. Presented at the 54th annual meeting of the American Academy of Dermatology. Washington, DC;996:P-317.

12 Bourke JF, Featherstone S, Igbal SJ, Hutchinson PE. A double-blind comparison of topical calcitriol $(3 \mu \mathrm{g} / \mathrm{g})$ and calcipotriol $(50 \mu \mathrm{g} / \mathrm{g})$ in the treatment of chronic plaque psoriasis vulgaris [abstract]. Br J Dermatol 1995;133(suppl 45):17.

13 Scarpa C. Calcipotriol: clinical trial versus betamethasone dipropionate + salicylic acid. Acta Derm Venereol (Stockh) 1994;186(suppl):47.

14 Hutchinson PE, Berth-Jones J, Chalmers RJG, Chu AC, Griffiths WAD, Klaber MR. A comparison of calcipotriol ointment and short contact dithranol in the treatment of chronic plaque psoriasis [abstract]. Br J Dermatol 1992;127(suppl 40): 17 .

15 Jurgensen HJ. A comparative study of Dovonex ointment and Dithrocream in treating psoriasis vulgaris [abstract]. Presented at the Dovonex Satellite symposium, 2nd Congress of the European Academy of Dermatology and Venereology. Athens, Greece 1991.

16 Lehmann P, Kerscher M. Combination phototherapy of psoriasis with calcipotriene and narrow-band (311 nm) UVB [letter]. J Am Acad Dermatol 1997:36:501-2.

17 Kerscher M, Volkenandt M, Plewig G, Lehmann P. Combination phototherapy of psoriasis with calcipotriol and narrow-band UVB [letter]. Lancet 1993;342:923

18 Kerscher M, Lehmann P, Plewig G. Combination phototherapy of psoriasis with calcipotriol and narrow-band UVB-light [abstract].J Invest Dermatol 1996;1:107.

19 Austad J. A comparative study of calcipotriol ointment in combination with UVB phototherapy and calcipotriol ointment alone in the treatment of psoriasis vulgaris [abstract]. Presented at the 27th Nordic Dermatology Congress. Finland, 1995

20 van de Kerkhof PCM. Calcipotriol cream and concurrent corticosteroids in psoriasis [abstract].J Eur Acad Dermatol Venereol 1995;5(suppl 1):S184.

21 Bourke JF, Berth-Jones J. Hutchinson PE. Occlusion enhances the efficacy of topical calcipotriol in the treatment of psoriasis vulgaris. Clin $E x p D$ matol 1993;18:504-6.
22 Berardesca E, Vignoli GP, Farinelli N, Vignini M, Distante F, Rabbiosi G. Non-invasive evaluation of topical calcipotriol versus clobetasol in the treatment of psoriasis. Acta Derm Venereol (Stockh) 1994;74:302-4.

23 Baadsgaard O, Traulsen J, Roed-Petersen J, Jakobsen HB. Optima concentration of tacalcitol in once-daily treatment of psoriasis. J Dermatol Treat 1995;6:145-50.

24 Austad J. Clobetasol propionate followed by calcipotriol is superior to calcipotriol alone in topical treatment of psoriasis [abstract]. Aust J Dermatol 1997;38(suppl 2):45.

25 Kragballe K, Beck HI, Søgaard H. Improvement of psoriasis by a topical vitamin $\mathrm{D}_{3}$ analogue (MC903) in a double-blind study. $\mathrm{Br} J$ Dermatol 1988:119:223-30

26 Staberg B, Roed-Petersen J, Menné T. Efficacy of topical treatment in psoriasis with MC903, a new vitamin D analogue. Acta Derm Venereol (Stockh) 1989;69:147-50.

27 Schwartzel E, Blum R, Siskin S, Epinette W. A parallel group study evaluating the safety of 30 gram per day dosing of calcipotriene (BMS181161/MC903) ointment and its vehicle in patients with plaque psoriasis [abstract]. Presented at the 54th annual meeting of the American Academy of Dermatology. Washington, DC;1996:P-287.

28 Köse O. Calcipotriol ointment vs clobetasol solution in scalp psoriasi [letter]. J Dermatol Treat 1997;8:287.

29 Mallett RB, Coulson IH, Purkis PE, Leigh IM, Holden CA. An immunohistochemical analysis of the changes in the immune infiltrate and keratin expression in psoriasis treated with calcipotriol compared with betamethasone ointment. Br J Dermatol 1990;123:837.

30 Arevalo A, Vega-Lopez F. Calcipotriol versus coal tar in Mexican patients with psoriasis [abstract].J Eur Acad Dermatol Venereol 1995;5(suppl 1):S92.

31 Katz HI, Lindholm JS, Wilde M, Siskin S, Wehr RW, Koeowald M, et al. A pilot, double-blind, bilateral, paired comparison of the efficacy, safety, and atrophogenic potential of calcipotriene ointment $0.005 \%$ versus its vehicle in the treatment of plaque psoriasis utilizing clinical evaluations and bioinstrumentation [abstract]. Presented at the 54th annual meeting of the American Academy of Dermatology. Washington, DC;1996:P-293.

32 Munro CS and study group. Calcipotriol soft cream in treatment of body psoriasis [abstract]. J Invest Dermatol 1996;1:111.

33 Van der Vleuten CJM, de Jong EMGJ, Rulo EHFC, Gerritsen MP, van de Kerkhof PCM. In-patient treatment with calcipotriol versus dithranol in refractory psoriasis. EurJ Dermatol 1995;5:676-9.

34 Ashcroft DM, Li Wan Po A, Williams HC, Griffiths CEM. Clinica measures of disease severity and outcome in psoriasis: a critical appraisal of their quality. Br J Dermatol 1999:141:185-91

(Accepted 7 December 1999)

\title{
Association between postnatal catch-up growth and obesity in childhood: prospective cohort study
}

Ken K L Ong, Marion L Ahmed, Pauline M Emmett, Michael A Preece, David B Dunger, and the Avon Longitudinal Study of Pregnancy and Childhood Study Team

\section{Abstract}

Objective To identify predictors of postnatal catch-up growth from birth to two years and its relation to size and obesity at five years.

Design Regional prospective cohort study.

Setting Avon longitudinal study of pregnancy and childhood, United Kingdom.

Subjects 848 full term singletons from a 10\% random sample of the Avon longitudinal study of pregnancy and childhood.

Main outcome measures Maternal birth weight, prepregnancy weight, pregnancy weight gain, height, smoking, and parity, and paternal height. Weight and length of infants at birth, two years, and five years expressed as standard deviation (SD) scores from the UK reference scores for 1990. Percentage fat mass and total fat mass (estimated from skinfolds) and waist circumference at five years.

Results Size at birth was representative of the national reference. Overall, 30.7\% (260 of 848) of infants showed a gain in SD score for weight greater than $0.67 \mathrm{SD}$ scores between zero and two years, indicating clinically significant catch-up growth. These children had lower weight, length, and ponderal index at birth than other children, and were more often from primiparous pregnancies. They also had taller fathers than other children, and their mothers had lower birth weights and were more likely to smoke during pregnancy. Children who showed catch-up growth between zero and two years were heavier, taller, and fatter (body mass index, percentage body fat, and waist circumference) at five years than other children.

Conclusions In this contemporary well nourished cohort, catch-up growth was predicted by factors relating to intrauterine restraint of fetal growth. Children who showed catch-up growth between zero and two years were fatter and had more central fat distribution at five years than other children. Mechanisms that signal and regulate early catch-up growth in the postnatal period may influence associations between small size at birth and risks for disease in adulthood.
Department of Paediatrics,

University of Oxford, John Radcliffe Hospital, Oxford OX3 9DU Ken K L Ong Medical Research Council clinical research fellow

Marion L Ahmed research assistant David B Dunger professor in paediatric endocrinology

Unit of Paediatric and Perinatal Epidemiology, University of Bristol, Bristol BS8 1TQ Pauline M Emmett senior research nutritionist

continued over

BMJ 2000;320:967-71 
Biochemistry, Endocrinology, and Metabolism Unit, Institute of Child Health, London WC1N 1AH Michael A Preece professor of child health and growth Correspondence to: D B Dunger dbd25@cam.ac.uk

\section{Introduction}

Associations between low birth weight, particularly thinness at birth, and increased risks for disease in adulthood, such as type 2 diabetes and cardiovascular disease, are now well established. In many population studies these associations are enhanced by and even depend on the development of obesity in adulthood. Therefore any relation between small size at birth and obesity in later life may contribute to the pathogenesis underlying the fetal origins hypothesis.

The greatest variation in rates of weight gain is seen in the first 1-2 years of life when infants may show significant "catch-up" or "catch-down" growth. These variable growth rates often compensate for intrauterine restraint or enhancement of fetal growth, and by two years of age growth usually follows the genetic trajectory. In recent birth cohort studies, subjects who were small or thin at birth and then showed rapid childhood growth had the greatest risk for disease in adulthood. In the geographically defined birth cohort of the Avon longitudinal study of pregnancy and childhood (ALSPAC), we now show that early postnatal catch-up growth, between birth and two years, is a risk factor for childhood obesity and may therefore contribute to associations between intrauterine growth restraint and risk of disease in adulthood.

\section{Subjects and methods}

\section{Subjects}

The ALSPAC cohort comprises 14000 children recruited from all births in the three Bristol based district health authorities between April 1991 and December 1992. We randomly selected a $10 \%$ subcohort from the last six months of recruitment, and we measured the infants at birth, every four months to 12 months, every six months to four years, and at five years. Of 1335 term (gestation 37-42 weeks) singletons in this subcohort there were complete data on weight at birth, two years, and five years for 848 infants (464 boys). Our analyses are confined to infants with complete data, and these were similar in birth weight to the remaining 487 infants without complete data. Ethical approval was obtained from the ALSPAC ethics committee and local ethics committees.

\section{Data collection and auxological measurements}

Gestation was estimated from the date of the last menstrual period and antenatal ultrasound reports (reviewed by professor Ian MacGillivray). Maternal birth weight, parity, and smoking during pregnancy were recorded by the mothers on a questionnaire, and maternal height and pregnancy weight gain were taken from obstetric records. Paternal height was self reported by questionnaire, completed by the mother's partner during the pregnancy.

Birth weights were noted from hospital records, and supine length was measured with a Harpenden neonatometer (Holtain, Crosswell, Dyfed) soon after birth (median one day, range 1-14 days) by a member of the ALSPAC study team. Weight (Seca 724 or 835 scales) and standing height (Leicester height measure, Child Growth Foundation) were measured in the research clinic at two and five years. At five years, subcutaneous skinfold measurements were taken in duplicate at four sites (biceps, triceps, subscapular, and suprailiac) with a Harpenden skinfold calliper (Holtain), and waist circumference was measured midway between the lowest rib and iliac crest by tape measure (Harpenden anthropometric tapes, Holtain).

\section{Calculations}

Ponderal index (weight/length ${ }^{3}$ ) at birth and body mass index (weight/length ${ }^{2}$ ) at two and five years were calculated as appropriate weight for length indices as these were independent of length. Percentage body fat was derived from four skinfold measurements from the equations of Brook and Siri, and fat mass was calculated as the product of percentage fat mass and weight. Natural logarithms of percentage body fat, total fat mass, and waist circumference were calculated as these were then normally distributed; geometric means (mean (SD) 95\% confidence interval) are therefore presented for these variables.

Using the UK growth reference for 1990, we calculated standard deviation (SD) scores independent of sex and age-that is, measurement minus population mean/population SD-in each infant for weight and length at birth; weight, height, and body mass index at two and five years; and maternal and paternal height. Changes in SD scores between birth and two years were calculated for weight and length (scores at two years minus scores at birth) and were adjusted for gestational age. A gain in SD score for weight between zero and two years that was greater than $0.67 \mathrm{SD}$ scores was taken to indicate clinically significant catch-up growth, as $0.67 \mathrm{SD}$ scores represent the width of each percentile band on standard growth charts-that is, second to ninth percentile, ninth to 25th, 25th to 50th, and so on. Similarly, a decrease in SD scores for weight by more than $0.67 \mathrm{SD}$ scores indicated catch-down growth.

\section{Statistics}

Associations between SD scores for weight at different ages were assessed with product moment correlations. We used analysis of variance to test differences in scores between children who showed catch-up, no change, or catch-down growth, and we used analysis of covariance when necessary to allow for sex and fat mass. We used $\chi^{2}$ test for linear trend to test for differences in parity, maternal smoking, and breast feeding. Statistics were analysed with SPSS for Windows (version 7.5.1)

\section{Results}

In our cohort, means and distribution of size at birth were similar to the UK growth reference for 1990 (table 1). By two years, however, boys were heavier than the national reference, and by five years both boys and girls were heavier, reflecting the current trends towards increasing weight gain in childhood.

\section{Change in SD score for weight $\mathbf{0 - 2}$ years}

The correlation between SD scores for weight at birth and at two years was low $(r=0.36, \quad \mathrm{P}<0.0005)$ compared with that between two and five years $(r=0.80, \mathrm{P}<0.0005)$, indicating large interindividual variation in rate of weight gain between birth and two years. Overall, $30.7 \%$ of infants (260) gained greater 
Table 1 UK 1990 standard deviation scores for size at birth, two years, and five years. Values are means (SDs) unless stated otherwise

\begin{tabular}{lccc} 
& Male & Female & Total \\
\hline Birth & & & \\
\hline Weight SD scores & $0.0(1.0)$ & $0.1(1.0)$ & $0.0(1.0)$ \\
\hline No & 464 & 384 & 848 \\
\hline Length SD scores & $0.1(1.0)$ & $0.1(1.0)$ & $0.1(1.0)$ \\
\hline No & 397 & 323 & 720 \\
\hline Two years & & & \\
\hline Weight SD scores & $0.2(1.0)^{\star *}$ & $0.0(1.0)$ & $0.1(1.0)$ \\
\hline No & 464 & 384 & 848 \\
\hline Height SD scores & $-0.1(0.9)$ & $-0.1(0.9)$ & $-0.1(0.9)$ \\
\hline No & 439 & 356 & 795 \\
\hline Body mass index SD scores & $0.4(1.0)^{* * *}$ & $0.1(1.0)$ & $0.3(1.0)$ \\
\hline No & 439 & 356 & 795 \\
\hline Five years & \multicolumn{4}{c}{} \\
\hline Weight SD scores & $0.3(1.0)$ & $0.3(1.0)$ & $0.3(1.0)$ \\
\hline No & 464 & 384 & 848 \\
\hline Height SD scores & $0.1(0.9)$ & $0.1(1.0)$ & $0.1(0.9)$ \\
\hline No & 461 & 380 & 841 \\
\hline Body mass index SD scores & $0.3(1.0)$ & $0.3(0.9)$ & $0.3(1.0)$ \\
\hline No & 461 & 380 & 841 \\
\hline Pviln & &
\end{tabular}

$\mathrm{P}$ value for sex difference: ${ }^{* \star}<0.005,{ }^{* * *}<0.0005$

than 0.67 SD scores between birth and two years indicating clinically significant catch-up growth, whereas $24.5 \%$ (208) lost more than 0.67 scores (catch-down growth); thus only $44.8 \%$ remained within the same weight percentile band between zero and two years. SD scores for length also showed significant catch-up (24.9\%, 174 of 700$)$ and catch-down $(20.7 \%, 145)$ growth, but these were less common (catch-up or catch-down $45.6 \%)$ than for weight $\left(55.2 \%, \chi^{2}\right.$ test: $\mathrm{P}<0.0005)$.

\section{Predictors for catch-up growth 0-2 years}

Children who showed catch up in SD scores for weight between zero and two years were lighter, shorter, and thinner at birth than those who showed no change (greater than -0.67 and less than 0.67 scores) or catch-down growth (table 2). These children also had taller fathers than other children, but there was no difference in either maternal height or body mass index (table 3) or prepregnancy weight or weight gain during pregnancy (data not shown). Catch-up growth between zero and two years was also related to low maternal birth weight and primiparous pregnancy, and there was a trend towards more mothers who admitted to smoking in pregnancy $(\mathrm{P}=0.07)$.

Catch-up growth 0-2 years and size at five years Children who showed catch up in SD scores for weight between zero and two years were heavier and taller and had greater body mass index, percentage body fat, and total fat mass than all other children at five years. They also had larger waist circumference at five years, and this difference persisted after allowing for body mass index $(\mathrm{P}=0.007)$ or fat mass $(\mathrm{P}=0.006)$. These results were unaffected by adjustment for breast or bottle feeding. Mean SD score for height at five years in children who showed catch-up growth (mean 0.47 SD 0.80 scores) was also greater than that of their mothers $(0.15$ SD 1.01, paired $t$ test: $\mathrm{P}<0.0005)$ or fathers $(0.05 \mathrm{SD}$ $0.92, \mathrm{P}<0.0005)$.
Even if catch-up growth was defined on the basis of gain in SD scores for length between zero and two years (greater than 0.67 scores), those who showed catch-up growth had greater body mass index SD scores (0.44 (1.01) scores) and fat mass (3.5 (1.2) kg) at five years than those who showed no change $(0.31$ (1.00); 3.3 (1.1)) or catch-down growth (0.23 (0.88); 2.9 (0.9)) ( $\mathrm{P}$ value for trend: body mass index $\mathrm{SD}$ scores $\mathrm{P}<0.05$; fat mass $\mathrm{P}<0.0005)$.

\section{Discussion}

Catch up is a property of human growth whereby children return to their genetic trajectory after a period of

Table 2 Size at birth, two years, and five years by change in weight standard deviation scores between zero and two years. Values are means (SDs) unless stated otherwise

\begin{tabular}{|c|c|c|c|}
\hline & \multicolumn{3}{|c|}{ Growth } \\
\hline & Catch-up & No change & Catch-down \\
\hline \multicolumn{4}{|l|}{ Birth } \\
\hline Weight SD scores & $-0.53(0.91)^{\star}$ & $0.01(0.86)$ & $0.69(0.96)$ \\
\hline No & 260 & 380 & 208 \\
\hline Length SD scores & $-0.23(0.98)^{\star}$ & $0.08(0.88)$ & $0.55(0.96)$ \\
\hline No & 231 & 318 & 171 \\
\hline Ponderal index $\left(\mathrm{kg} / \mathrm{m}^{3}\right)$ & $25.6(2.2)^{*}$ & $26.5(1.9)$ & $27.7(2.3)$ \\
\hline No & 231 & 318 & 171 \\
\hline \multicolumn{4}{|l|}{ Two years } \\
\hline Weight SD scores & $0.86(0.89)^{*}$ & $0.04(0.84)$ & $-0.62(0.89)$ \\
\hline No & 260 & 380 & 208 \\
\hline Height SD scores & $0.22(0.79)^{*}$ & $-0.13(0.87)$ & $-0.59(0.95)$ \\
\hline No & 246 & 357 & 192 \\
\hline Body mass index SD scores & $0.91(0.94)^{*}$ & $0.12(0.88)$ & $-0.34(0.94)$ \\
\hline No & 246 & 357 & 192 \\
\hline \multicolumn{4}{|l|}{ Five years } \\
\hline Weight SD scores & $0.87(0.93)^{\star}$ & $0.22(0.87)$ & $-0.29(0.93)$ \\
\hline No & 260 & 380 & 208 \\
\hline Height SD scores & $0.47(0.80)^{*}$ & $0.13(0.89)$ & $-0.37(0.98)$ \\
\hline No & 259 & 377 & 205 \\
\hline Body mass index SD scores & $0.82(1.01)^{*}$ & $0.19(0.87)$ & $-0.07(0.86)$ \\
\hline No & 259 & 377 & 205 \\
\hline Mean $(95 \% \mathrm{Cl})$ percentage body fat & $17.2(16.6 \text { to } 17.7)^{\star}$ & 15.8 (15.4 to 16.2) & 14.7 (14.2 to 15.2$)$ \\
\hline No & 199 & 333 & 173 \\
\hline Mean $(95 \% \mathrm{Cl})$ fat mass $(\mathrm{kg})$ & $3.6(3.4 \text { to } 3.7)^{\star}$ & $3.0(2.9$ to 3.1$)$ & 2.6 (2.5 to 2.8$)$ \\
\hline No & 199 & 333 & 173 \\
\hline $\begin{array}{l}\text { Mean }(95 \% \mathrm{Cl}) \text { waist } \\
\text { circumference }(\mathrm{cm})\end{array}$ & $54.6(54.2 \text { to } 55.1)^{\star}$ & 52.7 (52.3 to 53.0$)$ & $51.3(50.9$ to 51.8$)$ \\
\hline No & 258 & 377 & 207 \\
\hline
\end{tabular}

* $P$ value for trend: $<0.0005$

Table 3 Parental size and peripregnancy variables by pattern of change in weight standard deviation scores between zero and two years. Values are means (SDs) unless stated otherwise

\begin{tabular}{lccc} 
& \multicolumn{3}{c}{ Growth } \\
\cline { 2 - 4 } & Catch-up & No change & Catch-down \\
\hline Paternal details & $0.05(0.92)^{*}$ & $-0.07(0.95)$ & $-0.15(1.08)$ \\
\hline Height SD score & 199 & 268 & 145 \\
\hline No & & & \\
\hline Maternal details & $0.15(1.01)$ & $0.10(1.03)$ & $0.01(1.11)$ \\
\hline Height SD score & 247 & 366 & 202 \\
\hline No & $0.29(1.15)$ & $0.15(1.10)$ & $0.34(1.23)$ \\
\hline Body mass index SD score & 237 & 355 & 193 \\
\hline No & $3.20(0.57)^{*}$ & $3.34(0.59)$ & $3.34(0.53)$ \\
\hline Birth weight $(\mathrm{kg})$ & 170 & 231 & 130 \\
\hline No & $66^{* * *}(165 / 250)$ & $45.1(167 / 370)$ & $25.7(52 / 202)$ \\
\hline$\%$ (No) primiparous & $15.3(39 / 255)$ & $11.2(42 / 375)$ & $10.2(21 / 206)$ \\
\hline$\%$ (No) smoking in pregnancy & $40.1^{*}(101 / 252)$ & $51.5(188 / 365)$ & $51.3(102 / 199)$ \\
\hline$\%($ No) breast fed at 3 months & &
\end{tabular}

$\mathrm{P}$ value for trend: ${ }^{*}<0.05,{ }^{* *}<0.005,{ }^{* * *}<0.0005$ 
growth arrest or delay, for example, because of illness. It may occur at any stage of growth, but is most commonly observed in the first 1-2 years of life, and pronounced catch-up growth postnatally is often seen after severe intrauterine growth restraint.

In this contemporary and representative birth cohort, a large proportion of children (30.7\%) showed catch-up growth between zero and two years, sufficient to result in a move upwards by the width of at least one percentile band on standard growth charts. These children were lighter and thinner at birth than other children, and their mothers had had lower birth weights and also higher prevalence of primiparous pregnancy and smoking than the other mothers, indicating that fetal growth in these children had been restrained. The main determinants of fetal growth restraint in contemporary societies are not known. In this cohort, maternal diets during pregnancy have been shown to be adequate and unrelated to size at birth. Pregnancy induced hypertension and other maternal disease are also unlikely to be major factors as this cohort was recruited from healthy singletons at full term.

Children who showed catch-up growth had taller fathers than the other children. This may indicate a postnatal effect of paternal genes on childhood growth but could also be explained by increased maternal restraint in response to greater fetal growth potential, as suggested by crossbreeding experiments in animals. Catch-up growth was also related to low maternal birth weight. From observations of birth weights among extended human kindreds, Ounsted concluded that maternal restraint may be inherited as a trait through the maternal line. In this ALSPAC cohort, we recently showed an association between a common genetic variant in mitochondrial DNA and thinness at birth in infants who subsequently showed catch-up growth. Thus, interaction between maternally and paternally derived fetal genotypes could be an important determinant of fetal growth restraint and postnatal catch-up growth.

How infants who were restrained in utero catch up postnatally is largely unknown, although greater food intake has been observed compared with other infants. Concentrations of cord blood leptin are positively related to ponderal index at birth but inversely related to weight gain in infancy, and thus low concentrations of this hormone at birth may provide a signal for catch-up growth through reduced inhibition of satiety.

Children who showed catch up in weight or length between zero and two years were heavier and taller than other children at five years and they were also taller in relation to their mothers' and fathers' heights. Furthermore, these children had greater body mass index, percentage body fat, total fat mass, and central fat distribution, which are variables of childhood size linked to metabolic markers for risk of disease in adulthood and are predictive for adulthood obesity. Thus, in contemporary, affluent societies the biological predisposition to catch-up growth conferred by intrauterine restraint may result in an acceleration of growth postnatally that overshoots the genetic trajectory. A similar growth pattern has been observed in rodents exposed to experimental growth restraint in utero but allowed a plentiful food supply postnatally.

It is not known whether children who show postnatal catch-up growth will achieve final heights in
What is already known on this topic

The increased risks for diseases in adulthood, such as type 2 diabetes and hypertension, associated with small size at birth are exacerbated, and in some population studies only seen, in those subjects who become obese

What this study adds

The greatest variation in rates of weight gain occurs in the first 1-2 years of postnatal life

Infants who showed catch-up growth during this period were smaller and thinner at birth and had more maternal indicators of intrauterine growth restraint but were larger and fatter than other children at five years

Factors that signal and regulate postnatal catch-up growth may therefore contribute to the pathogenesis underlying the fetal origins hypothesis

excess of their genetic target, or rather whether their larger size at five years represents a faster rate of maturation. It is clear, however, that early postnatal catch-up growth, in a contemporary setting, leads to increased risk of central and peripheral obesity in childhood and potential risk for disease in adulthood. In contrast, catch-down growth in babies of large birth weight was related to thin size at five years and this finding is consistent with the continuum in decreasing risk of disease in adulthood with increasing size at birth, which extends across the whole range of birth weights. Further exploration of genetic and postnatal environmental factors that influence postnatal catch-up growth could uncover mechanisms whereby associations between size at birth and risks for disease in adulthood may be modified.

We thank the children and parents who took part and the midwives for their cooperation and help in recruitment. The ALSPAC study team comprises interviewers, computer technicians, laboratory technicians, clerical workers, research scientists, volunteers, managers, and the staff of the Children in Focus research clinics. The ALSPAC study is part of the WHO initiated European longitudinal study of pregnancy and childhood.

Contributors: PME and MAP contributed to the design of the ALSPAC children in focus study. Data collection and management was performed by the ALSPAC study team. KKLO, MLA, and DBD conceived the project, performed initial data analyses, and compiled the initial report. All authors contributed to further data analysis and writing of the paper. DBD will act as guarantor for the paper.

Funding: ALSPAC is supported by the Medical Research Council, the Wellcome Trust, the Department of Health, the Department of the Environment, and many others. DBD was also supported by the Wellcome Trust.

Competing interests: None declared.

1 O'Brien PM, Wheeler T, Barker DJ. Fetal programming: influences on develop ment and disease in later life. Proceedings of the 36th Royal College of Obstetricians and Gynaecologists Study Group. London: RCOG, 1999.

2 Lucas A, Fewtrell MS, Cole TJ. Fetal origins of adult disease-the hypothesis revisited. $B M J$ 1999;319:245-9.

3 Tanner JM. Growth from birth to two: a critical review. Acta Medica Auxologica 1994:26:7-45.

4 Tanner JM, Healy MJR, Lockhart RD, Mac-Kenzie JD, Whitehouse RH. Aberdeen growth study I. The prediction of adult body measurements from measurements taken each year from birth to five years. Arch Dis Child 1956;46:372-81.

5 Eriksson JG, Forsen T, Tuomilehto J, Winter PD, Osmond C, Barker DJ Catch-up growth in childhood and death from coronary heart disease: longitudinal study. BMJ 1999;318:427-31. 
6 Crowther NJ, Cameron N, Trusler J, Gray IP. Association between poo glucose tolerance and rapid post natal weight gain in seven-year-old children. Diabetologia 1998;41:1163-7.

7 Avon longitudinal study of pregnancy and childhood. Children of the nineties. alspac2.ich.bris.acuk/alspacext/Default (accessed 25 Oct 1999).

8 Brook CG. Determination of body composition of children from skinfold measurements. Arch Dis Child 1971;46:182-4.

9 Siri WE. Body composition from fluid spaces and density: analysis of methods. Nutrition 1993;9:480-91.

10 Freeman JV, Cole TJ, Chinn S, Jones PR, White EM, Preece MA. Cross sectional stature and weight reference curves for the UK, 1990. Arch Dis Child 1995;73:17-24.

11 Reilly JJ, Dorosty AR, Emmett PM. Prevalence of overweight and obesity in British children: cohort study. BMJ 1999;319:1039.

12 Tanner JM. Growth as a target-seeking function: catch-up and catch-down growth in man. In: Falkner F ed. Human growth; a comprehensive treatise. New York: Plenum, 1986:167-79.

13 Karlberg J, Albertsson Wikland K. Growth in full-term small-forgestational-age infants: from birth to final height. Pediatr Res 1995;38: 733-9.

14 Rogers I, Emmett P. Diet during pregnancy in a population of pregnant women in south west England. ALSPAC study team. Avon longitudinal study of pregnancy and childhood. Eur J Clin Nutr 1998;52:246-50.

15 Rogers I, Emmett P, Baker D, Golding J. Financial difficulties, smoking habits, composition of the diet and birthweight in a population of pregnant women in the south west of England. ALSPAC study team. Avon longitudinal study of pregnancy and childhood. Eur J Clin Nutr 1998:52:251-60.

16 Walton A, Hammond J. The maternal effects on growth and conformation in Shire horse-Shetland pony crosses. Proc $R$ Soc Lond 1938;125:311-35.
17 Ounsted M, Scott A, Ounsted C. Transmission through the female line of a mechanism constraining human fetal growth. Ann Hum Bio 1986;13:143-51.

18 Casteels K, Ong KK, Phillips DI, Bednarz A, Bendall H, Woods KA, et al. Mitochondrial 16189 variant, thinness at birth and type 2 diabetes. Lancet 1999:353:1499-500

19 Haig D. Altercation of generations: genetic conflicts of pregnancy. Am J Reprod Immunol 1996;35:226-32.

20 Ounsted M, Sleigh G. The infant's self-regulation of food intake and weight gain. Difference in metabolic balance after growth constraint or acceleration in utero. Lancet 1975;1:1393-7.

21 Ong KK, Ahmed ML, Sherriff A, Woods KA, Watts A, Golding J, et al. Cord blood leptin is associated with size at birth and predicts infancy weight gain in humans. J Clin Endocrinol Metab 1999;84:1145-8.

22 Freedman DS, Serdula MK, Srinivasan SR, Berenson GS. Relation of circumferences and skinfold thicknesses to lipid and insulin concentrations in children and adolescents: the Bogalusa heart study. Am J Clin Nut 1999;69:308-17.

23 Vanhala M, Vanhala P, Kumpusalo E, Halonen P, Takala J. Relation between obesity from childhood to adulthood and the metabolic syndrome: population based study. BMJ 1998;317:319-20.

24 Serdula MK, Ivery D, Coates RJ, Freedman DS, Williamson DF, Byers T Do obese children become obese adults? A review of the literature. Pres Med 1993;22:167-77.

25 Jennings BJ, Ozanne SE, Dorling MW, Hales CN. Early growth determines longevity in male rats and may be related to telomere shortening in the kidney. FEBS Letters 1999;448:4-8.

(Accepted 20 November 1999)

\title{
Factors underlying the effect of organisational downsizing on health of employees: longitudinal cohort study
}

\author{
Mika Kivimäki,Jussi Vahtera, Jaana Pentti, Jane E Ferrie
}

\begin{abstract}
Objective To explore the underlying mechanisms between organisational downsizing and deterioration of health of employees.

Design Longitudinal cohort study. Data were assembled from before downsizing (time 1); during major downsizing affecting some job categories (time 2); and after downsizing (time 3). Contributions of changes in work, support, and health related behaviours between time 1 and time 2 to the relation between downsizing and sickness absence at time 3 were assessed by multilevel modelling. Mean length of follow up was 4.9 years.

Setting Raisio, a town in Finland.

Subjects 764 municipal employees who remained in employment after downsizing.

Main outcome measures Records of absences from work from all causes with medical certificate.

Results Downsizing was associated with negative changes in work, impaired support from spouse, and increased prevalence of smoking. Sickness absence rate from all causes was 2.17 (95\% confidence interval 1.54 to 3.07) times higher after major downsizing than after minor downsizing. Adjustment for changes in work (for instance, physical demands, job control, and job insecurity) diminished the relation between downsizing and sickness absence by $49 \%$.

Adjustments for impaired social support or increased smoking did not alter the relation between downsizing and sickness absence. The findings were unaffected by sex and income.
\end{abstract}

Conclusions The exploration of potential mediating factors provides new information about the possible causal pathways linking organisational downsizing and health. Downsizing results in changes in work, social relationships, and health related behaviours. The observed increase in certificated sickness absence was partially explained by concomitant increases in physical demands and job insecurity and a reduction in job control. A considerable proportion of the increase, however, remained unexplained by the factors measured.

\section{Introduction}

Driven by alterations in the national and global economy, international competition, and the rapid pace of technological change organisational downsizing (that is, reduction in numbers of staff by businesses and other organisations) became an important aspect of working life in developed countries in the last decades of the 20th century. ${ }^{1}$ Regardless of whether downsizing is an effective business strategy resulting in better corporate performance, its potential deleterious consequences on the health of employees have become apparent. ${ }^{2-4}$ Vahtera et al, for example, reported that the health of those who kept their jobs depended on the extent to which staffing levels were reduced in the category of job concerned. ${ }^{3}$ Medically certified long term sickness absences, irrespective of cause, were twice as common after major downsizing $(>18 \%)$ than after minor downsizing $(<8 \%)$.
Department of Psychology, Division of Applied Psychology, University of Helsinki, PO Box

13, FIN-00014

University of

Helsinki, Finland

Mika Kivimäki senior researcher

Finnish Institute of

Occupational

Health,

Hämeenkatu 10,

FIN-20500 Turku,

Finland

Jussi Vahtera

senior researcher

Jaana Pentti

statistician

Department of Epidemiology and Public Health,

University College

London Medical

School, London

WC1E 6BT

Jane E Ferrie senior research fellow Correspondence to: M Kivimäki mika.kivimaki@ occuphealth.fi

BMJ 2000;320:971-5 